\title{
Comparative evaluation of the incidence of root microcracks observed within the canal wall after canal preparation using different rotary and reciprocating instruments
}

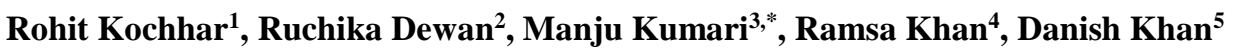 \\ ${ }^{1}$ Professor \& HOD, ${ }^{2,3}$ Professor, ${ }^{4,5}$ PG Student, Dept. of Conservative Dentistry and Endodontics, I. T. S. Dental College and \\ Hospital, Knowledge park III, Greater Noida, Uttar Pradesh, India
}

*Corresponding Author:

Email: docmanjukmr@gmail.com

\begin{abstract}
Introduction: Root microcracks may occur as a result of use of rotary cleaning and shaping instruments. It may be affected by the type and design of the rotary file system used to shape the root canal system.

Aim: The aim of this study was to compare the incidence of root microcracks observed within the canal wall after canal preparation using different rotary and reciprocating instruments.

Materials and Method: Fifty extracted single rooted anterior teeth were randomly assigned to 5 groups (N=10 teeth per group). The root canal preparation was done using TF Adaptive systems in Group 2, ProTaper Next in Group 3, WaveOne in Group 4 and Reciproc in Group 5. No instrumentation was done in Group 1. All the roots were horizontally sectioned 3, 6, and $9 \mathrm{~mm}$ from the apex and then viewed through a stereomicroscope at x 25 magnification.

Results: The control group had no cracks, and the difference between the control group and the experimental groups was statistically significant $(\mathrm{p}<0.05)$ at all the levels. At $3 \mathrm{~mm}$ level, Group $2 \& 3$ samples were found to have significantly less number of cracks than Group $4 \& 5$. At $6 \mathrm{~mm}$ level, there was no statistically significant difference among groups. At $9 \mathrm{~mm}$ level, Group 4 was found to have significantly lower number of cracks than Group 2.
\end{abstract}

Conclusion: All tested groups caused significantly more dentinal defect compared to the unprepared groups.

Keywords: Dentinal cracks, ProTaper Next, TF Adaptive systems, Reciproc, WaveOne.

\section{Introduction}

Biomechanical procedure with rotary instruments can possibly lead to root micro cracks which can possibly lead to root fracture. ${ }^{1}$ Various studies have reported that root microcracks can occur from use of Nickel-Titanium files in root dentin..$^{2-4}$ Technological advancements in the design and shape of Niti instruments are responsible for better faster and easier root canal shaping procedure. ${ }^{5}$ ProTaper Next (Dentsply Maillefer) instruments made from $M$ wire technology has introduced an off-centered rectangular design and progressive and regressive percentage taper. This design results in decrease of dangerous taper lock, the screw effect, and reducing torque on any file by decreasing the contact between the dentin and file. ${ }^{6}$

Recently, a new system called twisted file adaptive has been introduced. When it is exposed to minimal or no applied load it uses continuous rotation on the other hand when it engages dentin and a load is applied, it changes its mode from continuous to reciprocation mode with specific clockwise and counterclockwise angles varying from $600^{\circ}-0^{\circ}$ upto $370^{\circ}-50^{\circ} .^{7}$ Another new single file systems, Reciproc (VDW, Munich,Germany) and WaveOne (Denstply, Maillefer) made from $\mathrm{M}$ wire technology ${ }^{8}$ have been introduced and uses only 1 file to prepare the canal and thereby requiring less time than other file system. ${ }^{9}$ The design feature such as core diameter, rake angle, flute depth and cross-sectional shape may affect the behaviour of the file. ${ }^{10}$
Therefore, the aim of this study was to compare incidence microcracks within the root canal wall after canal preparation using different reciprocating files and NiTi rotary systems. The null hypothesis was that there would be no difference in crack formation at different root level among the groups.

\section{Material and Method}

Fifty extracted single rooted anterior teeth with straight canals were selected and stored in distilled water. All teeth were sectioned under water with low speed disc at $16 \mathrm{~mm}$ from the apex. The roots were then covered with a single layer of aluminium foil and embedded in acrylic resin. To stimulate the periodontal ligament, silicone light body-based material was applied over the covered root.

Access opening was done with a diamond bur (TR\#2). Number 10k-k file was used to determine the working length. Then the file was inserted till the root apex and $0.5 \mathrm{~mm}$ was substracted from this measurement. Number 15-k file type was used to prepare the glide path and then enlarged upto size $20 \mathrm{~K}$ file. The specimens were then divided 1 control and 4 experimental groups of 10 teeth each $(n=10)$ where biomechanical preparation(BMP) was done using following protocol:

Group 1: Negative control group wherein no BMP was performed

Group 2: Twisted File Adaptive system were used for BMP upto number 25/08 
Group 3: ProTaper Next Rotary instrument were used for BMP upto number 25/06

Group 4: WaveOne reciprocating system were used for BMP upto number 25/08

Group 5: Reciproc Rotary System was used for BMP upto number $25 / 08$

All samples were prepared apically to size \# 25 . During the biomechanical preparation, frequent irrigation was done using 3\% sodium hypochlorite 0.5 $\mathrm{ml}$ of distilled water was used to rinse the specimen of the prepared group. Sectioning of all the roots was done perpendicular to the long axis of the tooth at three different level (3, 6 and 9mm) using a diamond saw followed by stereomicroscopic evaluation at X20 magnification. Two different criteria were used to define the crack formation.

Root dentin devoid of cracks or micro cracks either at the internal or the external surface of the root canal surface was defined as "No defect". Any microcracks, fracture or craze lines if present in root dentin or extending to outer root surface was defined as "Defect".

The results were expressed as the number and percentage of cracked roots in each group. The data was analyzed with a Fischer exact test (with 95\% confidence level, $\mathrm{p} \leq .05$ statically significant). Statistical Package for Social Sciences software, 17.0 Version (SPSS, Chicago, Illinois, USA) was used for statistical analysis.

\section{Results}

The percentage and number of cracks in the study groups are shown in Table 1. No cracks were noticed in the control group and a statistically significant difference was observed between the control and experimental group $(\mathrm{p} \leq 0.05)$ at all the levels i.e., 3,6 and $9 \mathrm{~mm}$.

At $3 \mathrm{~mm}$ level, Group $2 \& 3$ samples were found to have significantly less number of cracks as compared to Group 4 \& 5. At $6 \mathrm{~mm}$ level, comparison between four experimental groups showed that there was no statistically significant difference. At $9 \mathrm{~mm}$ level, Group 4 was found to have significantly lower number of cracks as compared to Group 2.

Table 1: Percentage and number of cracks in study groups group

\begin{tabular}{|l|l|c|c|c|c|}
\hline \multicolumn{1}{|c|}{ Group } & & Apical & Middle & Coronal & Total \\
\hline \multirow{2}{*}{$\begin{array}{l}\text { Group 1 } \\
\text { (Control) }\end{array}$} & Count & 0 & 0 & 0 & 0 \\
\cline { 2 - 6 } & $\%$ within GR & $0.0 \%^{\mathrm{c}}$ & $0.0 \%^{\mathrm{c}}$ & $0.0 \%^{\mathrm{c}}$ & $0.0 \%$ \\
\hline \multirow{2}{*}{$\begin{array}{l}\text { Group 2 } \\
\text { (TF Adaptive) }\end{array}$} & Count & 1 & 5 & 6 & 12 \\
\cline { 2 - 6 } & $\%$ within GR & $10.0 \%^{\mathrm{a}}$ & $50.0 \%^{\mathrm{a}}$ & $60.0 \%^{\mathrm{a}, \mathrm{b}}$ & \\
\hline \multirow{2}{*}{$\begin{array}{l}\text { Group 3 } \\
\text { (ProTaper Next) }\end{array}$} & Count & 2 & 6 & 5 & 13 \\
\cline { 2 - 6 } & $\%$ within GR & $20.0 \%^{\mathrm{a}}$ & $60.0 \%^{\mathrm{a}}$ & $50.0 \%^{\mathrm{a}}$ & \\
\hline $\begin{array}{l}\text { Group 4 } \\
\text { (WaveOne) }\end{array}$ & Count & 6 & 4 & 3 & 13 \\
\cline { 2 - 6 } & $\%$ within GR & $60.0 \%^{\mathrm{b}}$ & $40.0 \%^{\mathrm{a}}$ & $30.0 \%^{\mathrm{a}, \mathrm{d}}$ & \\
\hline $\begin{array}{l}\text { Group 5 } \\
\text { (Reciproc) }\end{array}$ & Count & 5 & 5 & 4 & 14 \\
\cline { 2 - 6 } & $\%$ within GR & $50.0 \%^{\mathrm{b}}$ & $50.0 \%^{\mathrm{a}}$ & $40.0 \%^{\mathrm{a}}$ & \\
\hline
\end{tabular}

Same superscripts along the columns indicate non-significant difference

\section{Discussion}

In the present study, there was significant difference in crack formation at different root level among the groups; therefore the null hypothesis was rejected. Both TF Adaptive and ProTaper Next resulted in significantly less number of dentin cracks as compared to Wave one and Reciproc Rotary System at the apical third region. Samples within the control group showed no cracks on the external surface when observed under stereomicroscope before and after sectioning procedure. This shows that sectioning method used did not induce any cracks, therefore, cracks observed in the study groups were definitely due to the technique of root canal preparation.

The least amount of cracks observed in TFA could be attributed to the new adaptive reciprocating motion. This system when exposed to a minimal or no load uses continuous rotation and when it engages dentin and load is applied, it uses reciprocal motion. ${ }^{11}$ This adaptive movement might have decreased the stress concentration on the root canal wall resulting in less crack formation at the apical level

Kim et al. ${ }^{12}$ suggested that file design increases the apical stress and strain during instrumentation. ProTaper Next files have different cross-section design which could be the reason for the reduced dentinal cracks at the apical section in this study. According to Ruddle et al., ${ }^{6}$ decreased incidence of cracks in the tooth when ProTaper Next files were used may be due swaggering motion generated by the off- centered rectangular design of the file. This motion could decrease the screw effect, dangerous taper lock and torque on any given file by reducing the contact between the dentin and file. ${ }^{6}$

Burklein and others ${ }^{13}$ in their study found both Wave one and Reciproc to produce significantly more cracks than Protaper similar to the results of the present study. In their study more defects was created by 
reciorocating single file than Mtwo and Protaper files used in full rotary sequence. According to the authors in reciprocating system since single file is used till working length there is more chances of stresses on canal wall. In a study by Gergi et al. ${ }^{7}$ it was observed that both Reciproc and WaveOne produce significantly more cracks than TF Adaptive in the apical third of the root and correlated it with the cross-sectional design of the instrument. The WaveOne has a convex triangular cross section in the middle and coronal portion of the instrument with a modified triangular cross section with radial lands at the tip leading to reduced cutting efficiency and smaller chip space when compared to Reciproc having S-shaped geometry with a double cutting edge; however the difference was statistically insignificant.

Contrary to our findings, Berutti and others ${ }^{9}$ found that the Reciproc and wave one produced significantly less dentinal cracks then Protaper Next. According to the authors the Protaper next produces active rotating movement which causes high level of stress concentration in the walls of root canal that may have resulted in higher incidence of formation of cracks. Liu and others ${ }^{14}$ in their study reported only $5 \%$ of cracks when Reciproc was used in reciprocating motion whereas $50 \%$ craks when ProTaper universal files was used in full sequence rotary motion. Roane et al. ${ }^{15}$ and Mavani et al. ${ }^{5}$ found that incidence of root cracks was less when reciprocating wave one file was compared to multiple file system. According to the authors, reciprocating motion is similar to balanced force technique which could have minimized stresses both torsional and flexural. They also added WaveOne instrument is made from $\mathrm{M}$-wire, which is a more flexible variant of the NiTi alloy.

\section{Conclusion}

In the present study, Reciproc showed maximum number of cracks followed by WaveOne and ProTaper Next showing similar number of cracks and least by TF Adaptive system. Therefore, it can be concluded that rotary \& reciprocating file system tested in the present study caused significantly more dentinal defect compared to the unprepared groups.

\section{References}

1. Schäfer E, Lau R. Comparison of cutting efficiency and instrumentation of curved canal with nickel-titanium and stainless- steel instruments. J Endod 1999;25:427-30.

2. Tamse A, Fuss Z, Lustig J, Kaplavi J. An evaluation of endodontically treated vertically fractured teeth. J Endod 1999;25:506-8.

3. Bier CA, Shemesh H, Tanomaru-Filho M, Wesselink PR, Wu MK. The ability of different nickel-titanium rotary instruments to induce dentinal damage during canal preparation. J Endod 2009;35:236-8.

4. Ashwinkumar V, Krithikadatta J, Surendran S, Velmurgan N. Effect of reciprocating file motion on microcracks formation in root canals: an SEM study. Int Endod J 2014;47(7):622-7.
5. Mavani P, Pujar M, Uppin V, Vagarli H, Patil C, Yalagi $\mathrm{V}$. Comparative evaluation of root micro cracks by different rotary and reciprocating endodontic file systems. J Dent Med Sci 2015;14(9):18-22.

6. Ruddle CJ. The ProTaper endodontic system: geometrics, features and guidelines for use. Dent Today 2001; 20:607.

7. Gergi RM, Osta N E, Naaman SA. Dentinal crack formation during root canal preparation by twisted file adaptive, recip[roc and Waveone instruments. Eur J Dent 2015;9:508-12.

8. You SY, Kim HC, Bae KS, Baek SH, Kum KY, Lee W. Shaping ability of reciprocating motion in curved canals : A comparative study with micro-computed tomography. J Endod 2011;37:1296-300.

9. Berutti E, Chiandussi G, Paolino DS, Scotti N, Cantatore G, Castellucci A, et al. Canal shaping with Wave One Primary reciprocating files and Protaper system: A Comparative study. J Endod 2012;38:505-9.

10. Kim HC, Lee MH, Yum J, Versluis A, Lee CJ, Kim BM. Potential relationship between design of nickel titanium rotary instruments and vertical root fracture. J Endod 2010;36:1195-9.

11. Capar ID, Ertas H, Ok E, Arslan H, Ertas ET. Comparative study of different novel nickel-titanium rotary system for root canal preparation in severely curved root canals J Endod 2014;40:852-6.

12. Kim HC, Lee MH, Yum J, Versluis A, Lee CJ, Kim BM. Potential relationship between design of nickle-titanium rotary intruments and vertical root fracture. J Endod 2010;36:1195-9.

13. Bürklein $\mathrm{S}$, Tsotsis $\mathrm{P}$, Schäfer E. Incidence of dentinal defects after root canal preparation: Reciprocation versus rotary instrumentation. J Endod 2013;39:501-4.

14. Liu R, Hou BX, Wesselink PR, Wu MK, Shemesh H. The incidence of root microcracks caused by 3 different single- file systems versus the protaper system. J Endod 2013;39:1054-6.

15. Roane JB, Sabala CL, Duncanson MG. The "balanced force" concept for instrumentation of curved canals. J Endod 1985;11:203-11. 